\title{
The Values of Educational Character in the Arabic Temples of Qasidah Burdah by Imam Bushiri
}

\author{
${ }^{1}$ M. Rizalul Fuqon, ${ }^{2}$ Moh. Fery Fauzi* \\ ${ }^{1}$ Pesantren Ilmu Al-Quran (PIQ) Malang, Indonesia \\ e-mail : kangfurqon01@gmail.com \\ ${ }^{2}$ Universitas Muhammadiyah Malang, Indonesia \\ *Corresponding e-mail : mohferyfauzi@umm.ac.id
}

Abstract

This research aimed to determine the values of educational character in the Arabic temples of Qasidah Burdah by Imam Bushiri. The method used in this research was the descriptive analytical approach, which relies on the study of reality and phenomenon as it exists in reality and was concerned as an accurate description and expressed qualitatively and quantitatively. The results of the research were that the poem of Bosiri filled with rich educational behavioral values because many people read this poem and do not know its content and meaning in detail. Behavioral educational values in the poem of Bosiri are divided into four elements: 1) Behavioral educational values divinity, 2) personality, 3) social, 4) and moral. The verses concerning the behavioral educational values in this poem eighty-two beta.

Keyword Educational Character; Imam Bushiri; Qasidah Burdah; Value

$$
\begin{aligned}
& \text { هدف هذا البحث المتواضع إلى وصف القيم التربوية السلوكية. وكان المنهج } \\
& \text { المستخدم في هذا البحث هو المنهج الوصفي التحليلي الذي يعتمد على } \\
& \text { دراسـة الواقع والظاهرة كما يوجد في الواقع ويهتم بوصفها وصفا دقيقا ويعبر }
\end{aligned}
$$

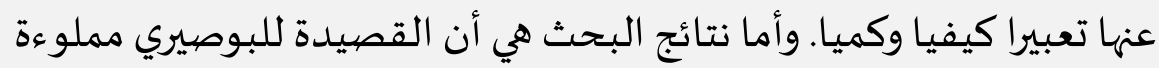

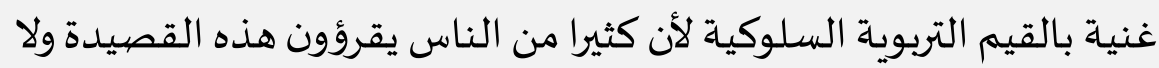

$$
\begin{aligned}
& \text { يعرفون مضمونها تفصيليا. وتنقسم القيم التربوية السلوكية في القصيدة }
\end{aligned}
$$

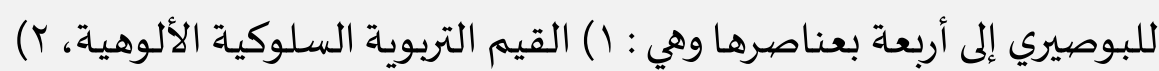

$$
\begin{aligned}
& \text { والشخصية، r) والاجتماعية، ع) والخلقية. والأبيات التي تتعلق بالقيم } \\
& \text { التربوية السلوكية في هذه القصيدة اثنتان وثمانون بيتا. }
\end{aligned}
$$

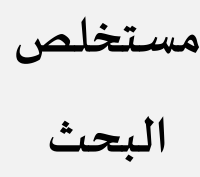

Please cite this article as M. Rizalul Furqon \& Moh. Fery Fauzi. (2019). The Values of Educational Character in the Arabic Temples of Qasidah Burdah by Imam Bushiri. Izdihār : Journal of Arabic Language Teaching, Linguistics, and Literature, 2(1), 67-76. DOI: 


$$
\text { قيم تربوية سلوكية؛ إمام بوصيري؛ قصيدة بردة ؛ قيم }
$$

\section{مقدمة}

قال مبارك في كتابه "المدائح النبوية" (مبارك, 19 هـ: 56 . مذه قصيدة البردة من أهم القصائد بين المدائح النبوية، فهي أولا : قصيدة جيدة، ثانيا : أسير القصيدة في هذا الباب، ثالثا : مصدر الوحي لكثير من القصائد التي أنشئت بعد البوصيري في مدح الرسول عليه السلام. ومن عجائبه أن هذه القصيدة تتأثر في أي مجالات الحياة والعلم لاسيما علوم اللغة العربية بالتفصيل: أثرها في الجماهير الشعبية، وأثرها في التأليف، وأثرها في الدرس، وأثرها في الأبيات، وأثرها في البديعات. ولهذا كله نرى من الواجب أن نعرض للبوصيري وقصيدته بشيء من التفصيل. والبردة في ذاتها لا تمكّن كل إنسـان من الكرمات، وإنما تنفعل النفس بما تؤمن به في صيدق واخلاص، فتمثل الغرائب والعجائب وكذلك كانت البردة عند بعض الناس مفتاحا للوصول بين يدي الرسول ولرؤيا النبي بحق: عند الصيوفية، وعند الفقهاء. وقصيدة البردة قصيدة عربية التي تمتاز بها على سائر القصيدات. وإنها لغة الفكر والثقافة والعقيدة (Masqon, 2018: p. 34) وهي

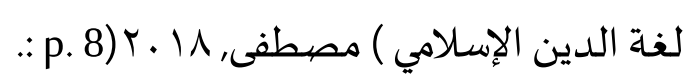

وكثير من الدلائل والبراهين التي تدل على أن هذه القصيدة قصيدة عظيمة منها، كثير من الناس يقرؤون هذه القصيدة في عدة البرامج المتنوعة حتى الآن بل كانوا يعتقدونها شفاء لمن قرأها.

كانت التربية في اللغة هي توصيل العلوم و المعلومات و الخبرات و القيم بطريق رسمي أو

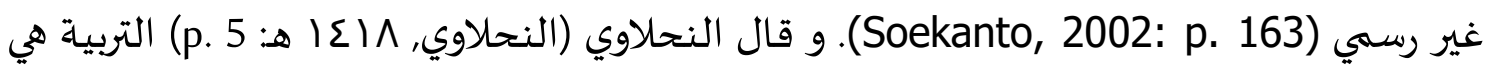
عملية مقصودة يوجه بها فرد أو أفراد، نحو أفراد آخرين، و يؤثرون في سلوكهم. و قال باغلي في يونس (Baglei) أعماله في المستقبل أتقن و أكمل.

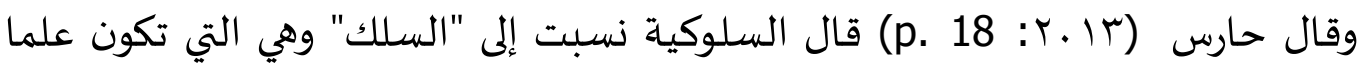
للشخص الذي يعيش في أي مكان كان وكذلك تكون طبيعة له. 
وقال سماني (11 ـ r: 36 .p) السلك هو كيفية فكرة الإنسان وعمله الطبيعي المستعمل للحياة والمعاملة بين العيال والأفراد والمجتمع والدول. يرى الباحث أن القيم التربويه السلوكية هي أمر ضروري في مسألة التربية حيث تودّ كل البلاد الموجودة في جميع أنحاء العالم لاسيما بلاد اندونيسيا كبلاد كبيرة - التي بلغ عدد سكانها حوالي اع Tليون نفس (Fauzi, 2019: p. 130) - أن تطبّق وتحقّق هذه التربية السلوكية، ومن ثمّ أنها يرى قصيدة البردة هي مجموعاة الأبيات المدحية العالية وكذلك أنه يرى فيها القيم التربوية بوجه عام وبالنسبة إلى أن كثيرا من قارئي هذه القصيدة لا يعرفون مضمونها الغني بالمنافع والبركات لاسيما القيم التربوية السلوكية فيها. ويحدد الباحث القيم التربوية السلوكية التي سوف تحل في

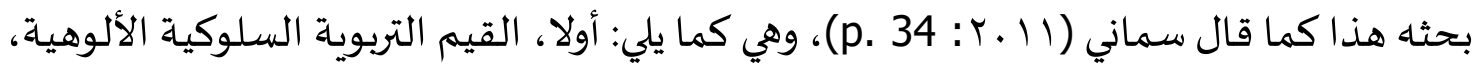
وأما عناصر القيم التربوية السلوكية الألوهية، كما يلي: (1) تقوى الله، وهي تتكون من العنصرين: الإيمان بالله وحده ومحبة الله تعالى ومحبة السول، و(T) عبادة الله تعالى وهي تتكون من ستة عناصر، وهي: إخلاص النية لله تعالى في جميع الأعمال، وإقام الصلاة، والدعاء إلى الله تعالى،

والشكر الله، والتوكل على الله، والتوبة إلى الله (TimDosenPAIIKIPMalang, 2009: p. 1). وثانيا، القيم التربوية السلوكية الشخصية، وذكر سماني (11 ـ ب: p. 79$)$ أن الواجبات المتعلقة بالشخصية السلوكية التي لابد أن تكون في نفس كل مسلم كثيرة جدا، ومنها ما يلي: (1) تنظيم الوقت، و(Y) الإتقان في العمل لكسب المعيشة، (r) الذكاء، (ع) الإتصال بالخير وإفشاء السلام، (0) الصدق والوفاء بالعهد، (7) الاعتماد على النفس، (V) الجد والنشاط، (^) الشجاعة،

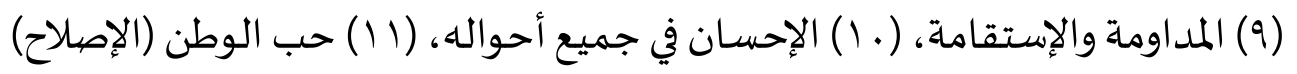

ثالثا، القيم التربوية السلوكية الاجتماعية، ومن واجبات المسلم في معاملته مع الآخر

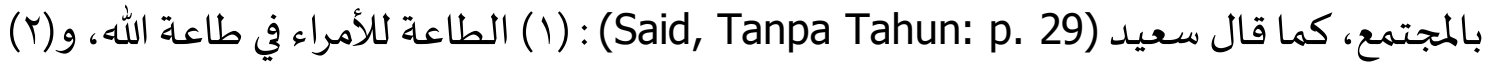
اختيار الصدق في الخير، و(T) المشاورة، و(ع) ربط الأخوة، و(0) الاتحاد، و(7) البرمع الآخر، و(V)

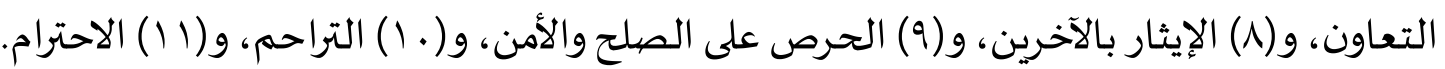
رابعا، القيم التربوية السلوكية الخلقية، وذكر السقاف (ع . .ب: 77 .p) أن من الأخلاق

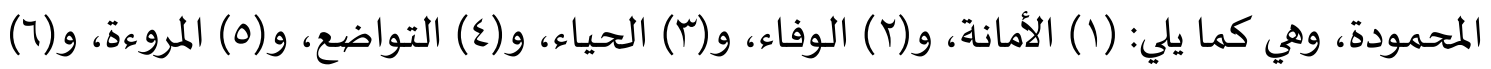
السخاء، و(V) حفظ النظافة، و(1) القناعة، و(9) السكينة، و( • () الرفق، و(1) حفظ اللسان. 
وأما من الأخلاق المذمومة فهي كما يلي: (1) أنانية، و(Y) البخل، و(r) سوء الظن، و(ع) الكبر، و(0) الرياء، و(7) التبذير، و(V) الشهوات، و(م) الكسل.

\section{منهج البحث}

المنهج المستخدم في هذا البحث هو المنهج الوصفي التحليلي الذي يعتمد على دراسة الواقع

والظاهرة كما يوجد في الواقع ويهتم بوصفها وصفا دقيقا ويعبّر عنها تعبيرا كيفيا وكميا. قالت حياتي (p. الأسلوب الوفصي هو الأسلوب الذي يعتمد على دراسة الواقع أو الظاهرة. وبيانات

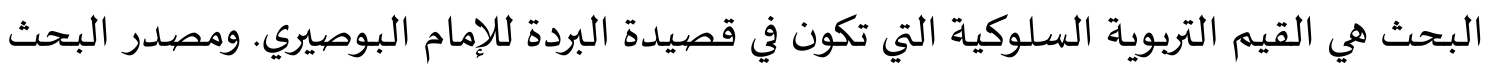

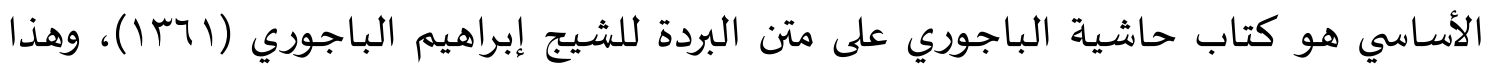
الكتاب يكون كتابا أساسيا اعتمد إليه الباحث في تحليل أبيات القصيدة والبحوث والكتب المتعلقة بالقيم التربوية السلوكية وكذلك المتعلقة بقصيدة البردة. أدوات البحث الأساسية في هذا البحث هي الباحث نفسه (Human Instrument) لأنه يقوم بالتصميم، والتصنيف، وجمع المعلومات، والتحليل، وتأويل المعلومات، وتقرير البحث.

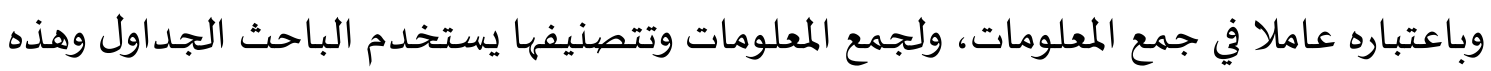

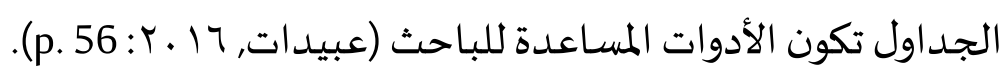

\section{بحث ومناقشة}

ضوءًا بما سبق عن أقسام القيم من القيم التربوية السلوكية الألوهية في أبيات قصيدة البردة، والقيم التربوية السلوكية الشخصية في أبيات قصيدة البردة، والقيم التربوية السلوكية الاجتماعية في أبيات قصيدة البردة، والقيم التربوية السلوكية الخلقية في أبيات قصيدة البردة، ففي هذا العرض يقدم الباحث نتائج البحث كما يلي:

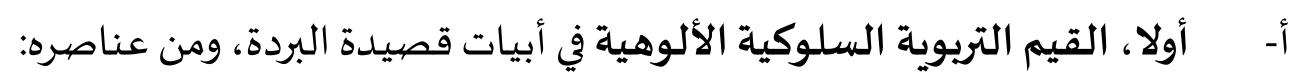

تقوى الله تعالى، والعبادة إلى الله تعالى. وتقوى الله تعالى تتكون من ثلاثة عناصر، وهي :

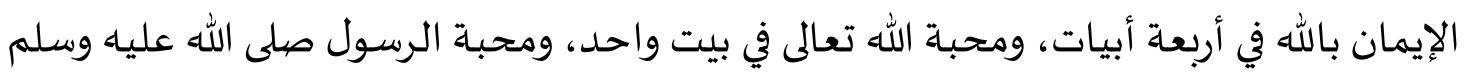


في أحد عشر بيتا وفي النسيب من قصيدة البردة تتكون من اثني عشر بيتا. وأما العبادة إلى الله

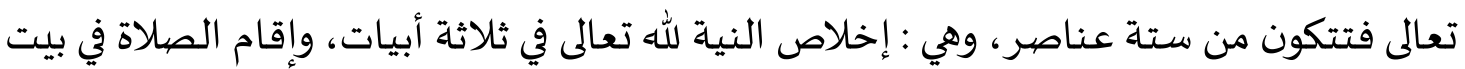
واحد، والدعاء إلى الله في ثلاثة أبيات، والشكر لله تعالى في بيتين اثنين، والتوكل على الله في بيت واحد، والتوبة إلى الله في بيتين اثنين. وعدد الأبيات للقيم التربوية السلوكية الألوهية في قصيدة البردة دون تكرار ستة وثلاثون بيتا.

وكانت هذه النتيجة توافق على ما قاله (TimDosenPAllKIPMalang, 2009: p. 17) عناصر القيم التربوية السلوكية الألوهية، كما يلي: (1) تقوى الله، وهي تتكون من ثلاثة عناصر : الإيمان بالله وحده ومحبة الله تعالى، ومحبة الرسول، و(Y) عبادة الله تعالى وهي تتكون من ستة عناصر، وهي: إخلاص النية لله تعالى في جميع الأعمال، وإقام الصلاة، والدعاء إلى الله تعالى، والشكر الله، والتوكل على الله، والتوبة إلى الله.

كان العنصر " محبة الرسول ومدحه " أكثر القيم التي قد وجدها الباحث من العناصر

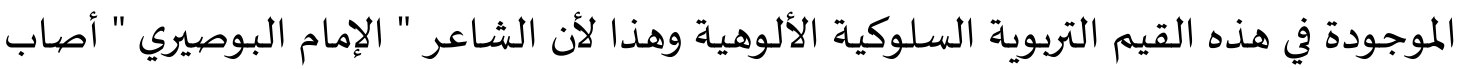

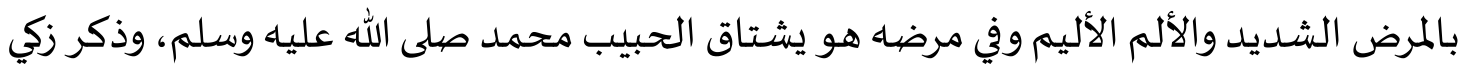

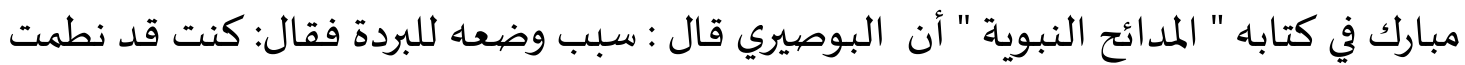
قصائد في مدح رسول الله صلى الله عليه وسلم منها ماكان اقترحه عليّ الصاحب زين الدين يعقوب لئه بن الزبير، ثم اتفق بعد ذلك أن صاحبني فالج أبطل نصفي، ففكرت في عمل هذه القصيدة فعملتها حتى الانتهاء، واستشفعت بها إلى الله في أن يعافيني ويشفيني، وكررت إنشادها ودعوت وتوسلت حتى نمت فرأيت النبي صلى الله عليه وسلم، فمسح النبي وجهي بيده المباركة، وألقى النبي عليّ البردة وقرأت عليه هذه القصيدة وبعدها انتهت وقمت من نومي ومن المعقول أن يبرأ مريض من مرضها لآية يتلوها أو قصيدة ينشدها كما برئ البوصيري من مرضهاه بقصيدتها.

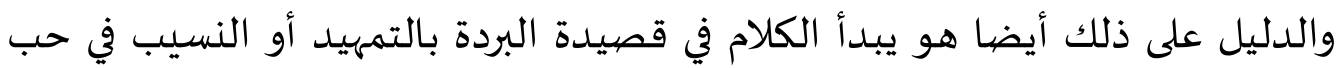
الرسول صلى الله عليه وسلم حوالي اثنا عشر بيتا : وهي عندما يتكلم الشاعر عن هيامه الشديد لمعشوقها بذكر الأمكنة التي تتعلق بحياة ذلك المعشوق، وتلك هي "ذي سلم" في البيت الأول، و

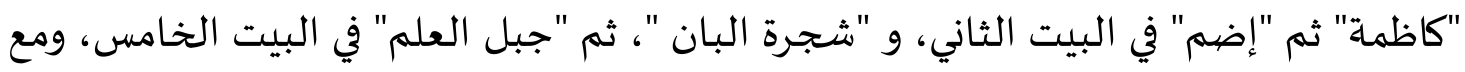


ذلك هو يتكلم عن بكائه الشديد شوقا لمعشوقه في البيت الأول، ودقات قلبه في البيت الثالث، السقم والأرق في البيت السادس، وصمممه عن العذّال في البيت الحادي عشر.

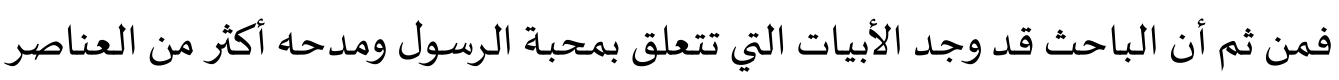
الأخرى الموجودة في هذه القيم التربوية السلوكية الألوهية. ب- ثانيا، القيم التربوية السلوكية الشخصية الموجودة في أبيات قصيدة البردة سبعة البردة البردية عناصر، وهي: الإتقان في العمل لكسب المعيشة في بيت واحد، وتنظيم الوقت في ثلاثة المانة

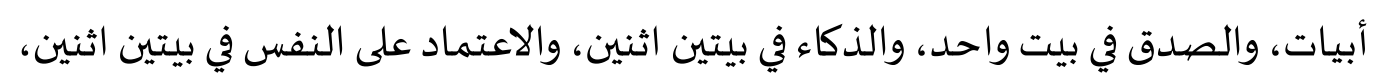
والجد والنشاط في بيت واحد، والشجاعة في ثلاثة أبيات. وعدد الأبيات للقيم التربوية السلوكية الشخصية في قصيدة البردة دون تكرار ثلاثة عشر بيتا. وكانت هذه النتيجة أقل مما ذكره " سماني" (Samani, 2011: p. 79) أن الواجبات المتعلقة بالشخصية السلوكية التي لابد أن تكون في نفس كل مسلم كثيرة جدا، ومنها ما يلي: (1) تنظيم الوقت، و(Y) الإتقان في العمل لكسب المعيشة، (؟) الذكاء، (ع) الإتصال بالخير وإفشاء

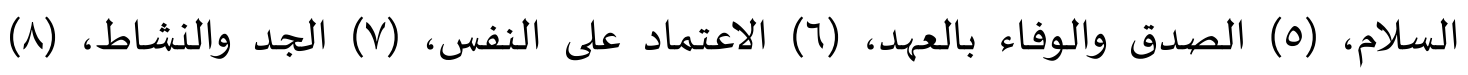

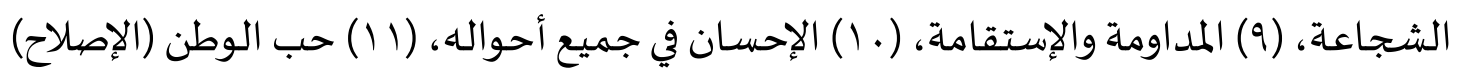

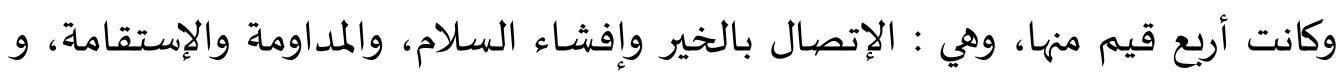
الإحسان في جميع أحواله، وحبّ الوطن (الإصلاح) ما وجدها الباحث في أبيات قصيدة البهات البردة.

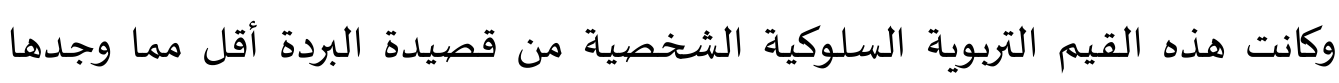

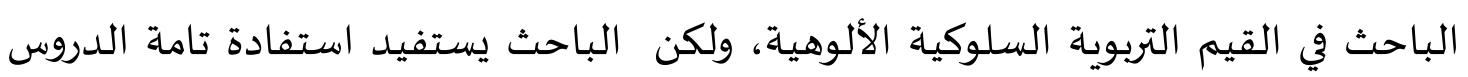
والخبرات الموجودة في العنصر " تنظيم الوقت " هناك تعليم ودرس من الشاعر مثلا في إحذاره عن دسائس الجوع والعطش وكذلك استحبابه في قراءة البسملة في أول الأمر كله والاختتام

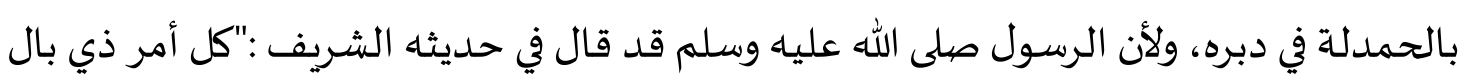

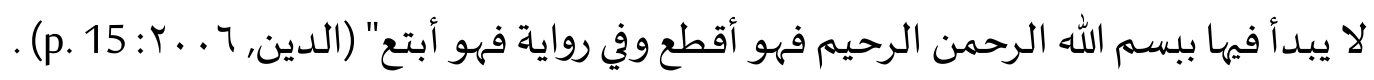

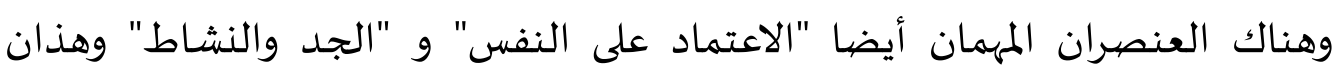

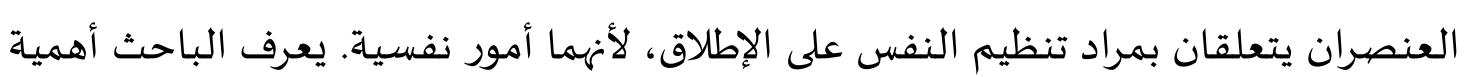
عدم القنوط في العمل وكذلك أن العمل يحتاج إلى الجد والنشاط فيهاه. 
ج- الثا، القيم التربوية السلوكية الاجتماعية الموجودة في أبيات قصيدة البردة أربعة عناصر، وهي: ربط الأخوة في بيت واحد، والإتحاد في بيتين اثنين، والتعاون في ثلاثة أبيات، واختيار الصديق في الخير في بيت واحد. وعدد الأبيات للقيم التربوية السلوكية الاجتماعية في قصيدة البردة دون تكرار ستة أبيات.

وهذه النتيجة أقل مما ذكره سعيد (Tanpa Tahun: p. 29) : ( ) الطاعة للأمراء في طاعة الله، و(ץ) اختيار الصدق في الخير، و(r) المشاورة، و(ع) ربط الأخوة، و(0) الاتحاد، و(7) البرمع الآخر، و(V) التعاون، و(^) الإيثار بالآخرين، و(9) الحرص على الصلح والأمن، و(• () التراحم، و(1) (1) (1) الاحترام.

وكانت ست قيم منها، وهي : (1) الطاعة للأمراء في طاعة الله، والبر مع الآخر، والإيثار بالآخرين، والحرص على الصلح والأمن، والتراحم، والاحترام، والمشـاورة، ما وجدها الباحث في أبيات قصيدة البردة.

وها هي ذه القيم التي صعب للباحث أن يجدها في أبيات قصيدة البردة، قال مبارك (19 19 هـ 71 . في " المدائح النبوية " أنّ حياة البوصيري الاجتماعية هي حياة محزنة لأن البوصيري في حياته الاجتماعية قد احتقره المجتمع وكذلك السكان الذين يعيشون في زمانه، قيل هذا بسبب كثرة أولاده بل كان زين الدين يعقوب بن الزبير عندما جاء للبوصيري قد حملت زوجتاه، ومن هذا الحال يبتعد عنه السكان ويحتقره.

فلذلك أن الباحث وجد القيم التربوية السلوكية الاجتماعية أقل مما سبق ذكره من القيم التربوية السلوكية الألوهية والقيم التربوية السلوكية الشخصية بالنظر إلى حياة البوصيري

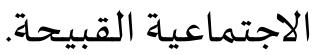

د- رابعا، القيم التربوية السلوكية الخلقية الموجودة في أبيات قصيدة البردة التي استنتجها الباحث اثنا عشر عنصرا. وتنقسم إلى قسمين، وهما : أولا : ستاة عناصر للأخلاق المحمودة، وهي : التواضع في أربعة أبيات، والمروءة في ثلاثة أبيات، والسكينة في بيت واحد، وحفظ النفس في ثلاثة أبيات، والقناعة في بيت واحد، والزهد في بيتين اثنين. وثانيا : ستـة عناصر للأخلاق المذمومة،، وهي : سوء الظن في بيت واحد، والكبر في بيتين اثنين، والشهوات 
في ثلاثة أبيات، والكسل في ثلاثة أبيات، والندم في بيتين اثنين، والإنكار في بيت واحد. وعدد الأبيات للقيم التربوية السلوكية الخلقية في قصيدة البردة دون تكرار أربعة وعشرون بيتا.

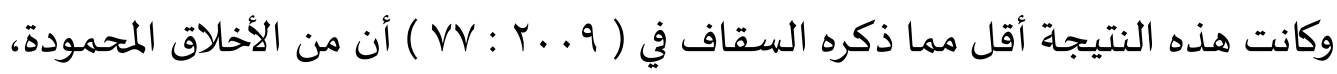

وهي كما يلي: (1) الأمانة، و(Y) حفظ النفس، و(ץ) الحياء، و(ع) التواضع، و(0) المروءة، و(7) الزهد، و(V) حفظ النظافة، و(1) القناعة، و(9) السكينة، و( • ( ) الرفق، و(1) حفظ اللسان. وأما من الأخلاق المذمومة فهي كما يلي: (1) الندم، و(Y) البخل، و(r) سوء الظن، و(ع) الكبر، و(0) الإنكار، و (7) التبذير، و(V) الشهوات، و(^) الكسل. وكانت خمس قيم من عناصر الأخلاق المحمودة، وهي : الحياء، وحفظ النظافة، والرفق، و حفظ اللسان، والأمانة، ما وجدها الباحث في أبيات قصيدة البردة. وكذلك قيمتان اثنتان من عناصر الأخلاق المذمومة، وهي : البخل، والتبذير، ما وجدهما الباحث في أبيات قصيدة البردة. وجد الباحث في القيم التربوية السلوكية الخلقية الأخلاق العديدة المتنوعة محمودة كانت أم مذمومة، حيث يبين الباحث تلك الأخلاق تفصيلية، فالمرجو من الباحث للقراء بعد معرفة الأخلاق المحمودة من أبيات هذه القصيدة هم يتخلّقون بهذه الأخلاق ويتمثّلون بما كانت في هذه الأخلاق وبالعكس، بعد ما عرفوا الأخلاق المذمومة الموجودة في قصيدة البردة هم لا يتمثّلون بتلك الخلاق المذمومة ولا يتخلّقون بهذه الخصال الرذيلة التي تسبب إلى عدم النجاح في نيل

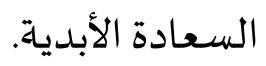

وبيّن البوصيري الأخطار من هوى النفس الكثيرة منها : هو يأمر الإنسان بأن لا يطيعه لأن النفس وهواه يُصنم أو يَهِيم حيث قال في أحد أبياته " إن الهوى ما تولى يصهم أو يصهم " وكذلك قارن البوصيري اللفظ "النفس" و "الشيطان" في أحد أبياته، هذان الشيئان يدلان على أنّ لهما علاقة متينة قوية، وعرف الإنسان أن النفس كثيرا ما جاءت من همزات الشياطين أولا، فلذلك علينا الإصراف عنهما في نيل السعادة الأبدية.

خاتمة

إن أكثر الأبيات التي قد وجـدها الباحث في قصيدة البردة هي الأبيات التي تكون في القيم التربوية الألوهياة، لاسيما في العنصر "محبـة الرسول ومدحاء" هذا يدل على شـوق الشاعر للنبي صلى 
الله عليه وسلم عظيم وكذلك أن البوصيري أنشأ هذه القصيدة أثناء إصابته بالمرض الشديد الذي يعجزه حتى لايستطيح أن يتحرك. وبعد الإتمام في كتابة هذه القصيدة هو يرى النبي في منامه وألقى النبي عليه البردة وقراً حضرت النبي هذه القصيدة وبعدها انتبه وقام من نومه، ومن المعقول أن يبرأ مريض من مرضها لآية يتلوها أو قصيدة ينشدها كما برئ البوصيري من مرضها بقصيدته.

إضافة إلى نتائج البحث فالمرجو من الباحث الآخر أن يبحث في غير القيم التربوية السلوكية

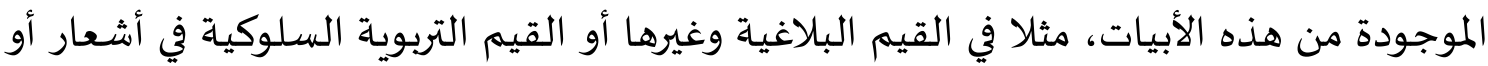

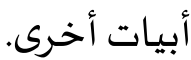

وبما أن لهذا الكتاب أهميته في توسيع آفاق الطلاب العلمية فيستحسن أن يعدّ قسم الأدب العربي الكتاب المذكور أو أمثاله ويجعل هذا البحث العلمي كتابا مقررا في الدراسة أو لزيادة الكتاب

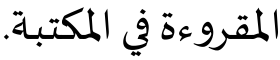

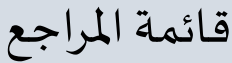

Fauzi, M. F. A., Irma. (2019). تطوير اللغز الرقمي لمادة التطبيق الصرفي ا على الماسل Buletin Al-Turas, 25(1), 129-139. doi: https://doi.org/10.15408/bat.v25i1.11506

Haris, M. A. (2013). Kata-Kata Mutiara Bahasa Arab Inspirasi Pendidikan Karakter Islami. Yogyakarta: Diandra Creative

Hayati, F. A. (2018). لفظ القسم ومرادفاته في السور المدنية. Izdihar: Journal of Arabic Language Teaching, Linguistics, and Literature, 1(2), 137-152. doi: 10.22219/izdihar.v1i2.7296

Masqon, D. (2018). دور اللغة العربية في عصر العولمة وتطبيقها في تطوير العلوم. Izdihar: Journal of Arabic Language Teaching, Linguistics, and Literature, 1(1), 25-64. doi: 10.22219/izdihar.v1i1.6562

Said, M. (Tanpa Tahun). Adab Tata Susila dalam Al Quran. Bandung: Al Maarif.

Samani, M. (2011). Konsep dan Model Pendidikan Karakter. Bandung: Remaja Rosdakarya Offset.

Soekanto, S. (2002). Sosiologi Suatu Pengantar. Jakarta: Rajawali. 
TimDosenPAIIKIPMalang. (2009). Aktualisasi Pendidikan Islam Respon terhadap Problematika Kontemporer. Malang: Hilal Pustaka.

الباجوري, إ. (الباجوا). حاشية الباجوري على متن البردة تأليف شيخ الإسلام الشيخ

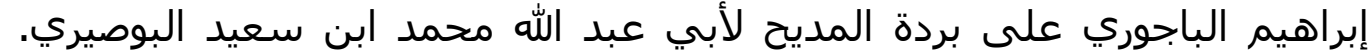
إندونيسيا: الحرمين سنقافورة جدة.

الدين, إ. ع. (7 • †). جلاء الأفهام شرح عقيدة العوام. سورابايا: دار العلوم الاسلامية.

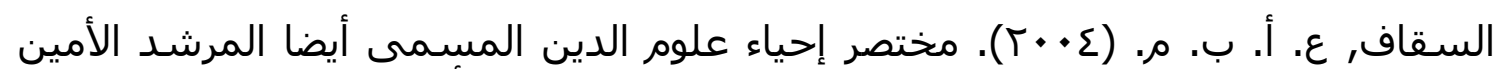

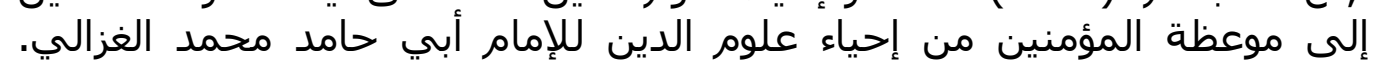
إندونيسيا: دار الكتب الإسلامية.

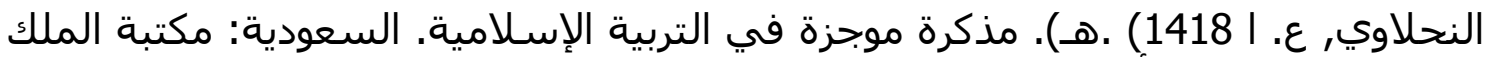

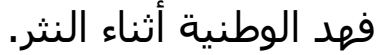

عبيدات, ذ. (7) • ( ). البحث العلمي في مفهومه، أدواته و أساليبه. جاكرتا: دار الفكر

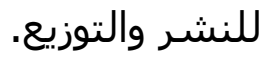

مبارك, ز. (9Y0 هـ). المدائح النبوية في الأدب العربي. قاهرة: دار الكاتب العربي للنشر والطباعة.

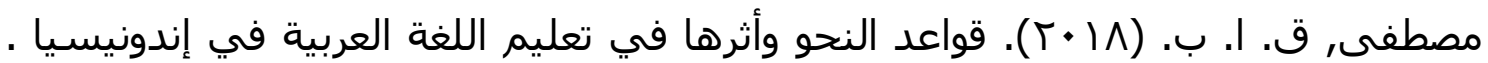
Izdihar: Journal of Arabic Language Teaching, Linguistics, and Literature,

1(1), 1-24. doi: 10.22219/izdihar.v1i1.6560

يونس, م. (9MV) (19Y2). الأديان. جاكرتا: مكتبة السعدية فترا. 